\title{
Entropy and Multi-Objective Based Approach for Groundwater Quality Monitoring Network Assessment and Redesign
}

\author{
Y. Mogheir • J. L. M. P. de Lima • V. P. Singh
}

Received: 29 March 2006 / Accepted: 1 September 2008 /

Published online: 17 September 2008

(C) The Author(s) 2008. This article is published with open access at Springerlink.com

\begin{abstract}
Selection of the number and location of groundwater quality monitoring wells may require the consideration of different aspects such as: monitoring objectives, temporal frequency of monitoring, and monitoring costs. These aspects were examined using observations of groundwater quality variables made twice a year in 124 wells in the northern part of the Gaza Strip, where groundwater is of the best quality. Considering these features the groundwater quality monitoring network was assessed and redesigned using entropy. The assessment procedure was based on expressing transinformation as a function of distance between wells. It was found that the number and location of groundwater quality monitoring wells varied if these aspects were embedded in the assessment and redesign procedure.
\end{abstract}

Keywords Groundwater quality monitoring • Entropy • Transinformation • Information • Gaza Strip

Y. Mogheir $(\varangle)$

Department of Environmental Engineering,

Islamic University of Gaza, Gaza, Palestine

e-mail: ymogheir@iugaza.edu.ps

J. L. M. P. de Lima

Department of Civil Engineering, Institute of Marine Research-Coimbra

Interdisciplinary Centre, Faculty of Science and Technology-Campus 2,

University of Coimbra, 3030-788, Coimbra, Portugal

e-mail: plima@dec.uc.pt

V. P. Singh

Department of Biological and Agricultural Engineering,

Texas A and M University, Scoates Hall, 2117 TAMU,

College Station, TX 77843-2117, USA

e-mail: vsingh@tamu.edu 


\section{Introduction}

Long-term monitoring is essential in surface and groundwater management and for tackling changing environmental issues. In some regions, such as the Gaza Strip, Palestine, a great deal of attention is directed toward groundwater, since it is the only water resource available. In the Gaza Strip there are severe groundwater quality deterioration problems, such as increasing salinity. In developing regions, such as the Gaza Strip, protection and control measures are started by establishing groundwater monitoring networks. The monitoring practices are undertaken for collecting data which might not necessarily be needed or might not provide the information to be sought. As a result, the monitoring network features, such as the spatial distribution of wells, the variables to be observed and the temporal frequency of observation, may not be adequately determined from the network observations. Consequently, these regions may waste a lot of money (Mogheir 2003).

The definition of the monitoring objectives plays a significant role in defining monitoring network features, such as the number of monitoring wells and the temporal frequency of monitoring (e.g., Loaiciga et al. 1992; Meyer et al. 1994; Cox et al. 1997; Mogheir 2003). Mogheir et al. (2003c) defined the objective as the determination of regional salinity in the Gaza Strip aquifer and assessed and redesigned the monitoring network accordingly. Only one variable was considered [chlorine $(\mathrm{Cl})$ ], as an indicator of salinity, for the assessment and redesign procedure. If the objective of monitoring is changed to include the monitoring of Electrical Conductivity (EC) as an indicator of the total solids in the groundwater, and Nitrate $\left(\mathrm{NO}_{3}\right)$ as an indicator of the groundwater deterioration due to infiltrated sewage, then the question arises: What are the number and density of monitoring wells required to fulfill this objective? This study attempts to answer this question.

Once the objective of monitoring is specified, the most important features to be defined for assessing and redesigning a groundwater monitoring network are: spatial location of monitoring wells and temporal frequency of monitoring (number of times per year the water quality parameters are to be measured). Several studies have considered network design based only on the assessment of spatial locations (e.g., Rouhani and Hall 1988; Loaiciga 1989; Cressie 1990; Caselton and Zidek 1991; Cox et al. 1997; Bueso et al. 1998). Therefore, assessment and design based on the temporal frequency of monitoring has been discussed by Quimpo and Yang (1970), Sanders and Adrian (1978), Zhou (1996), among others. Studies combining spatiotemporal monitoring design or redesign are relatively sparse (e.g., Rodriguez-Iturbe and Mejia 1974; Stein et al. 1998). Temporal frequency of monitoring is important in the design of a groundwater monitoring network. On one hand, by monitoring too often (monitoring per unit time is too high), the information obtained is redundant and therefore a waste of effort, since a large portion of the cost of monitoring is normally related to the temporal frequency of monitoring. On the other hand, by monitoring too little, some important information may be missed and the objective of monitoring may not be met. Thus the question arises: What is the appropriate temporal frequency for monitoring groundwater quality?

Generally, the aim of any monitoring network is to collect needed information with least cost. The groundwater quality monitoring is an expensive, time consuming and uncertain process. In developing regions, such as Gaza Strip, budgets usually are limited and are not able to support such programs over a long period of time. 
Therefore, the need to develop cost-effective monitoring programs in these regions has recently received special attention (e.g., ASCE 1990; Patrick et al. 2000; Mogheir 2003). The cost of monitoring is a major factor that influences the design of the monitoring network. The network design is ultimately combined with the cost of monitoring (e.g., Radford and West 1986; Andricevic 1990; Mahar and Datta 1997), which may vary from place to place (developing or developed regions).

Entropy theory has been used to evaluate the spatial location, temporal frequency, and the combined spatio-temporal frequency of monitoring networks (e.g., Harmancioglu and Alpaslan 1992; Yang and Burn 1994; Mogheir 2003). The effect of each feature upon the network efficiency and cost effectiveness was discussed using entropy-based measures. For example, the effect of extending the monitoring interval from monthly to bimonthly measurements for three variables investigated was found to lead to a significant loss of information regarding dissolved oxygen, $\mathrm{Cl}$ and EC. The selection of an appropriate temporal frequency of monitoring was made by assessing how much information the decision maker would risk versus the given cost of monitoring. A similar evaluation was made with respect to the number and location of required sampling sites, where changes in the rate of information gain were investigated with respect to the number of stations in the network. Harmancioglu and Alpaslan (1992) combined both spatial and temporal frequencies to assess the variation of information with respect to space and time. These analyses have shown the applicability of entropy in the network assessment.

This study attempts to present a methodology for assessing and redesigning a groundwater quality monitoring network by reducing both the redundant information and the cost of monitoring. To obtain a cost-effective design, the objective of monitoring (what to measure), spatial distribution of monitoring wells (where to measure) and temporal frequency of monitoring (when to measure) were considered. The methodology described here was applied to a case study from the Gaza Strip, Palestine.

\section{Gaza Strip Data}

The Gaza Strip has approximately $365 \mathrm{~km}^{2}$ and is located on the eastern extremity of the Mediterranean Sea (Fig. 1). It is bordered by the Mediterranean Sea in the West and the Negev Desert and Egyptian Sinai Peninsula in the south. The Gaza Strip area (Fig. 1) has a length of $45 \mathrm{~km}$ from Beit Hanon in the north to Rafah in the south. It is divided into five Governorates: Northern, Gaza, Middle, Khanyounes and Rafah. Each Governorate has its own municipal administration.

High concentrations of salinity $(\mathrm{Cl})$ and Nitrate $\left(\mathrm{NO}_{3}\right)$ in the aquifer are the major water quality problems in the Gaza Strip. In many areas of this region, these concentrations exceed the WHO drinking water standards for $\mathrm{Cl}(250 \mathrm{mg} / \mathrm{l})$ and $\mathrm{NO}_{3}$ (50 mg/l). The source of $\mathrm{Cl}$ may be: (1) seawater intrusion where it extends inland in the range from 1.0 to $2.5 \mathrm{~km}$; (2) lateral inflow of brackish water $(\mathrm{Cl}=500-$ $2000 \mathrm{mg} / \mathrm{l}$ ) from Israel in the middle and the southern areas of the Gaza Strip; and (3) the presence of deep brines at the base of the coastal aquifer $\left(\mathrm{Cl}=4\right.$ to $\left.6 \times 10^{4} \mathrm{mg} / \mathrm{l}\right)$, with overpumping resulting in the upconing of this brine. The main sources of $\mathrm{NO}_{3}$ are fertilizers and domestic sewage effluents (Mogheir 2003). 
Fig. 1 Location map of Gaza Strip, Palestine

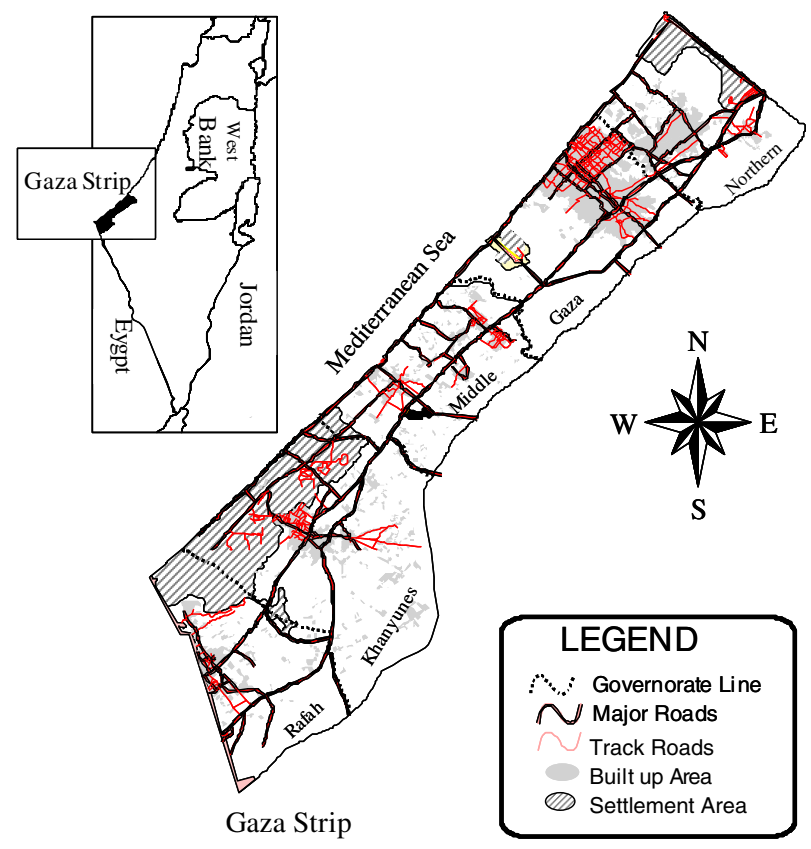

In the Gaza Strip, the groundwater monitoring networks are divided according to: (1) groundwater level, (2) groundwater quality, and (3) municipal wells. The groundwater level network measures the groundwater level on a monthly base, using approximately 130 agricultural wells. The groundwater quality network measures three variables: $\mathrm{EC}, \mathrm{Cl}$ and $\mathrm{NO}_{3}$. These measurements are made twice a year using approximately 400 agricultural wells (e.g., Mogheir and Singh 2002). The third type of monitoring network consists of municipal wells which measure: EC, Total Dissolved Solids, Calcium, Magnesium, Sodium, Potassium, $\mathrm{Cl}, \mathrm{NO}_{3}$, Sulphate, Alkalinity and Hardness. For this purpose, approximately 100 municipal wells are used. The measurements are made twice a year, once in summer and once in winter. The three networks are used to collect information that describes the groundwater quality and quantity status of the Gaza Strip Aquifer (Mogheir et al. 2003c).

The Palestinian Water Authority (PWA) considers the Northern Governorate as a priority area to be controlled and protected from pollution, because it has a strategic groundwater reservoir. The best quality groundwater can be found in this area. In this article the groundwater quality monitoring network in the Northern Governorate is used as a case study. Nevertheless, the analyses of these sections can be expanded to cover all the Gaza Strip Governorates. Note that the time series of $\mathrm{EC}$ and $\mathrm{NO}_{3}$ should be screened and checked for the rest of Gaza Strip Governorates before expanding the methodology.

In this study, the number of groundwater quality monitoring wells used in the Northern Governorate was 124 (Fig. 2). These wells monitor $\mathrm{Cl}$ and $\mathrm{EC}$ and $\mathrm{NO}_{3}$ twice a year in the period 1972 to 2000 . 


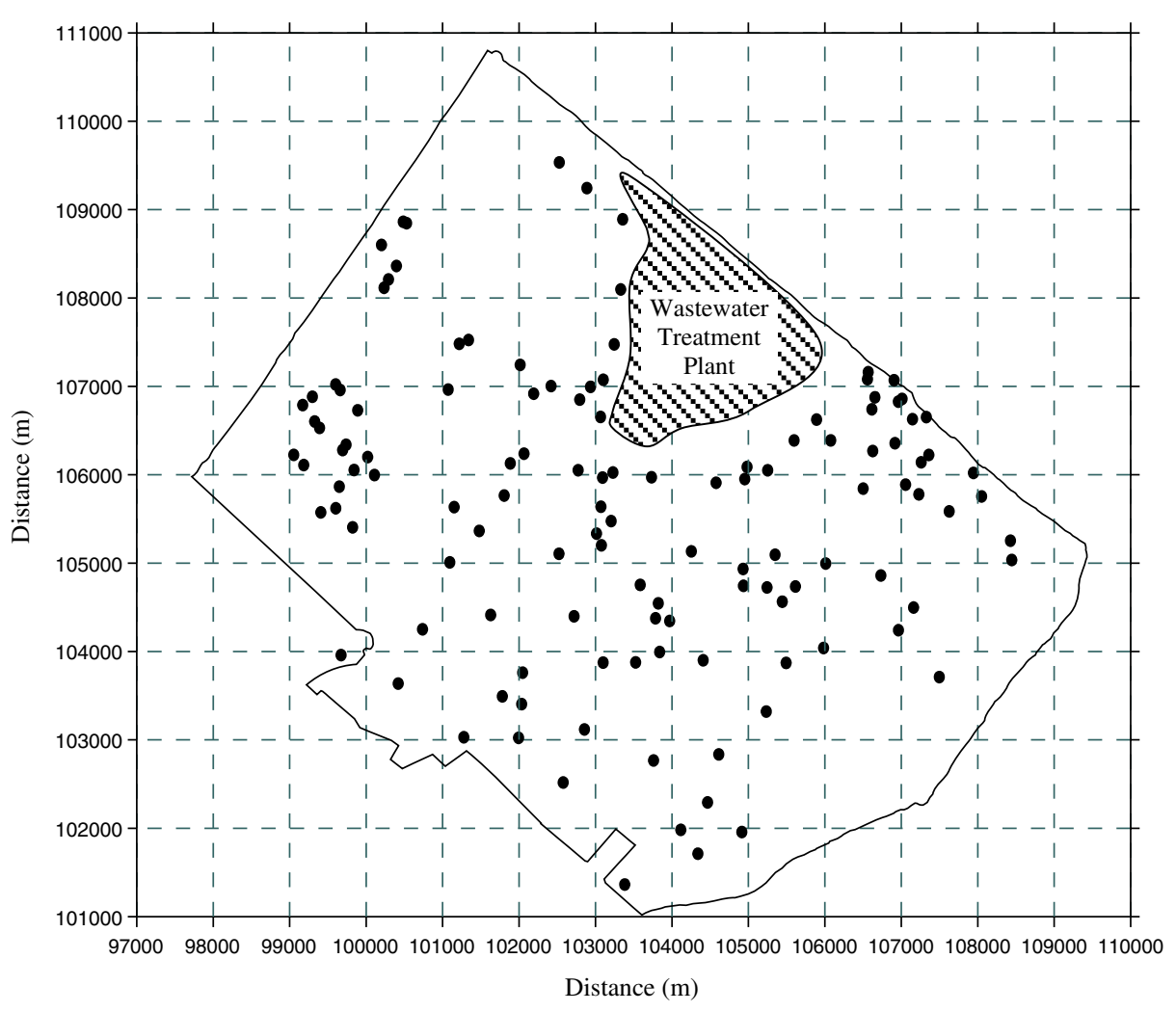

Fig. 2 Location of existing groundwater quality monitoring wells in the Northern Governorate (filled circle). The number of wells is 124

\section{Methodology}

\subsection{Entropy-Based Measures}

The assessment and redesign of the location of groundwater quality monitoring wells was first made using Chloride as a variable observed in a number of monitoring wells. That was achieved by characterising the spatial variability of the variable at different locations. The spatial variability was described by means of transinformation as a function of distance between wells (Mogheir et al. 2003a, b). Transinformation ( $T$ ) was determined as:

$$
T\left(x_{z i}, x_{h j}\right)=-\sum_{i=1}^{n} \sum_{j=1}^{n} p\left(x_{z i}, x_{h j}\right) \ln \left[\frac{p\left(x_{z i}, x_{h j}\right)}{p\left(x_{z i}\right) p\left(x_{h j}\right)}\right]
$$

$x_{z i}$ represents the groundwater quality variable (Chloride), where $z(z=1, \ldots, Z)$ denotes the well identification number and $i$ the time-point along the sample of size $\mathrm{n}(i=1,2, \ldots, n), x_{h j}$ is the value of this variable observed at a distance $d(\mathrm{~m})$ away from $x_{z i}$, where $h \neq z$ and $j=1,2, \ldots, n$, defined in the same probability space, the 
discrete probabilities of occurrence of both wells are $p\left(x_{z i}\right)$ and $p\left(x_{h j}\right)$, respectively; and $p\left(x_{z i}, x_{h j}\right)$ is the joint probability of $x_{z i}$ and $x_{h j}$.

The joint probability $p\left(x_{z i}, x_{h j}\right)$ was obtained using contingency tables (e.g., Gokhale and Kullback 1978; Mogheir and Singh 2002; Mogheir et al. 2004), which records the frequency of the values that fall into each possible combination of two categories. The spatial dependency was measured by transinformation as a function of distance between wells ( $T$-Model; Mogheir et al. 2003b). The exponential decay curve was fitted to the $T$-Model data. The exponential decay of the $T$-Model $(T(d))$ was represented as (Mogheir et al. 2003a, c):

$$
T(d)=\left(T_{0}-T_{\min }\right) e^{\left(-K_{T} d\right)}+T_{\min }
$$

where $T_{0}$ is the initial value of transinformation; $K_{T}$ is the transinformation decay rate; $T_{\min }$ is the minimum transinformation value $\left(T_{\min }\right)$; and $d$ is the distance between wells. The distance at which the transinformation model approaches a constant minimum value is called the range $\left(L_{T}\right)$. The estimation of the range $L_{T}$ is important for the assessment of the spatial location of the monitoring wells. For an exponential decay curve, $T(d)$ approaches $T_{\min }$ asymptotically and, therefore, the $L_{T}$ value is estimated when $T(d)$ is very close to $T_{\min }$ as:

$$
L_{T}=\frac{\ln \left(T_{0}-T_{\min }\right)-\ln (\varepsilon)}{K_{T}}
$$

where $\varepsilon$ is a constant number and its unit is Nats (provided that the used logarithmic base is $e$ ) (Mogheir et al. 2003a).

For more accurate computation, one should compute the net transinformation, since the $T$-Model steadily decreases to a minimum value $\left(T_{\min }\right)$ which differs from zero. Practically, that is not accurate, since the minimum Transinformation should be equal zero. Therefore, the Net $T$ is computed as:

$$
T(d)^{\mathrm{NET}}=T(d)-T_{\min }
$$

The wells were assessed using the percentage of the Net Redundant Information (\% NRI) between wells as (Mogheir et al. 2003c):

$$
\% \mathrm{NRI}=\frac{T(d)^{\mathrm{NET}}}{T_{0}-T_{\min }} \times 100
$$

The maximum NRI available in the network was computed according to the minimum distance existing between two wells. In such a case the NRI value indicates further steps required for redesigning the location of wells in the monitoring network, either by reducing the number of wells when available wells have distances more than the minimum and less than the designed distance or expanding the monitoring network, when the available wells have distances greater than the designed distance and in this case NRI is minimum. The number of wells was reduced by superimposing $a$ square $a \times a \mathrm{~m}^{2}$ over the monitored area and selecting one well per square block in a stratified way (e.g., Mogheir et al. 2003c). Then, the recommended grid size was obtained as:

$$
a=0.5\left(L_{T}\right) \cos 45=0.354 L_{T}
$$




\subsection{Cost-Informativeness Analysis}

It is desirable that the cost of monitoring be reduced to meet the stated objectives. For estimating the cost of monitoring, it is necessary to determine all the resources and associated costs required to ensure the collection of information-rich data. Generally the cost of monitoring is subdivided into:

1. The cost of monitoring vehicle $\left(\mathrm{Cost}^{\mathrm{V}}\right)$ which includes the cost of used fuel and the maintenance of vehicle;

2. cost of laboratory analyses $\left(\operatorname{Cost}^{\mathrm{L}}\right)$; and

3. cost of the salaries of monitoring staff $\left(\mathrm{Cost}^{\mathrm{S}}\right)$ which includes the cost of collecting the samples, data handling, and interpretation.

Therefore, the estimated cost of monitoring is computed as:

$$
\operatorname{Cost}^{\mathrm{M}}=\operatorname{Cost}^{\mathrm{V}}+\operatorname{Cost}^{\mathrm{L}}+\operatorname{Cost}^{\mathrm{S}}
$$

where $\operatorname{Cost}^{\mathrm{M}}$ is the cost of monitoring in US\$ per well, $\operatorname{Cost}^{\mathrm{V}}$ is the operational cost of monitoring vehicle, $\operatorname{Cost}^{\mathrm{L}}$ is the cost of laboratory analyses per well and $\operatorname{Cost}^{\mathrm{S}}$ is the salary of monitoring staff per well. Therefore, the total cost of monitoring is computed as:

$$
\operatorname{Cost}^{\text {Total }}=\operatorname{Cost}^{\mathrm{M}} \times(\text { number of wells })
$$

where, Cost ${ }^{\text {Total }}$ is the total cost of monitoring for any number of wells. The costinformativeness relation was obtained by plotting the net redundant information percentage computed by Eq. 4 against the total cost of monitoring computed by Eq. 8. This section was tailored for the case of the Gaza Strip. The detailed computation of the cost of monitoring in the Gaza Strip is shown in Section 4.2.

\subsection{Multi-Objective Approach}

The methodology presented in Section 3.1 was tested by changing the objective of monitoring and the temporal frequency. The monitoring network was redesigned and the cost-effective relation was obtained by considering different objectives of monitoring and temporal frequency. For example, the approach of Section 3.1 was examined for the case of monitoring $\mathrm{EC}, \mathrm{NO}_{3}$ and $\mathrm{Cl}$. It was also tested by increasing the temporal frequency of monitoring to once a year and once every 2 years.

\section{Applications}

\subsection{Spatial Assessment and Redesign for One Variable (Chloride)}

The above methodology was applied to the Northern Governorate of the Gaza Strip where the existing groundwater quality monitoring network comprises 124 wells. Figure 2 shows the location of these wells, which monitor salinity in the Gaza Strip aquifer and are operated by the Ministry of Agriculture. The analysis was applied to $\mathrm{Cl}$ for the years 1972 to 2000 on a bimonthly basis. $\mathrm{Cl}$ was considered as an indicator of the salinity in the Gaza Strip aquifer. 
The $T$-Model for $\mathrm{Cl}$ was obtained by computing the $T$ values using Eq. 1 and the distance between wells. The exponential decay curve was fitted to the $T$-Model data using the least square technique. The $T$-Model of $\mathrm{Cl}$ in the Northern Governorate is expressed as

$$
T(d)=0.9860 e^{(-0 . .0034 d)}+0.4583
$$

Equation 3 was used to determine the value of $L_{T}$. In this equation $\varepsilon$ is considered to be small and equals 0.0001 Nats. Under these conditions, the $L_{T}$ value of the $T$ Model in the Northern Governorate was selected at the point where the $T$-Model asymptotically reached the distance axis. Therefore, Table 1 shows parameters $\left(T_{0}, T_{\min }, K_{T}\right.$ and $\left.L_{T}\right)$ of the exponential decay of the $T$-Model in the Northern Governorate.

The minimum existing distance between wells in the Northern Governorate was found to be less than the $L_{T}$ value. The minimum distance was $48.8 \mathrm{~m}$. Then, the maximum redundant information (net), which was computed using Eq. 5, equalled $85 \%$. This indicates that the location of the existing monitoring wells in the Northern Governorates needs redesigning by reducing the number of wells. The reduction was based on the criterion that a minimum redundant information should be allowed between wells. This amount of redundant information may be decided by the decision maker. To overcome this issue, the designer may provide several scenarios from which the number and location of wells that give the minimum redundant information in the network can be selected.

Based on the assessment of the spatial location of wells, it was found that the spatial location of existing monitoring wells was inadequate and significant redundant information existed. Therefore, a systematic network should be determined and should offer less redundant information. The existing monitoring wells should be reduced to allow a minimum NRI percentage. That was achieved by considering the $T$-Model parameters, specifically $T_{\min }$ and $L_{T}$. The redesign criterion was to select the distance between wells, which gave the minimum NRI.

The superimposition approach was used to redesign the monitoring wells by specifying different scenarios based on specified grid sizes. For each Governorate, four scenarios were evaluated using different grid sizes $(500,1,000,1,500 \mathrm{~m}$ and a distance $D=a$ computed from Eq. 6). In each scenario, a regular square grid was superimposed over the monitored area and one well per square block was selected in a stratified pattern. Different scenarios gave different design outputs: percentage of NRI (using Eq. 5) and percentage of reductions in wells. The four scenarios for the Northern Governorate are presented in Table 2.

The fourth scenario is the recommended or the best-found scenario. This was achieved by selecting the distance between wells equal to $L_{T}$. For example, from $L_{T}$, which was estimated to be $2,705 \mathrm{~m}$, a regular square grid $958 \times 958 \mathrm{~m}$ was specified using Eq. 6. The network in the Governorate was then reduced by superimposing the square pattern over the monitored area and selecting one well per square block in a stratified way. The existing network was reduced by $60 \%$. The NRI was $23 \%$,

Table $1 \mathrm{~T}(\mathrm{~d})$ parameters for $\mathrm{Cl}$ in the Northern Governorate

\begin{tabular}{llll}
\hline$T_{0}$ (Nats) & $T_{\min }($ Nats $)$ & $K_{T}(1 / \mathrm{m})$ & $L_{T}(\mathrm{~m})$ \\
\hline 1.4443 & 0.4583 & 0.0034 & 2705 \\
\hline
\end{tabular}


Table 2 Redesign scenarios applied to the existing monitoring network in the Northern Governorate

\begin{tabular}{llllrcc}
\hline Scenarios & $\begin{array}{l}a(\text { Grid size) } \\
(\mathrm{m})\end{array}$ & Max. distance $(\mathrm{m})$ & $\begin{array}{l}\text { Min. existing } \\
\text { distance } \\
(\text { existing) }\end{array}$ & $\begin{array}{l}\text { NRI } \\
(\%)\end{array}$ & $\begin{array}{l}\text { No. of } \\
\text { wells }\end{array}$ & $\begin{array}{l}\text { Reduction } \\
\text { in wells } \\
(\%)\end{array}$ \\
\hline Existing situation & - & - & 48 & 85 & 124 & 0 \\
Scenario 1 & 500 & 1414 & 210 & 50 & 89 & 38 \\
Scenario 2 & 1000 & 2828 & 540 & 16 & 46 & 63 \\
Scenario 3 & 1500 & 4242 & 814 & 7 & 27 & 78 \\
Recommended & 958 & $2705=L_{\max }$ & 428 & 23 & 49 & 60 \\
scenario & & & & & & \\
\hline
\end{tabular}

which was not reduced fully, since the minimum distance between wells is $428 \mathrm{~m}$. There are areas where the distance is greater than $L_{T}$ and such areas need additional monitoring wells. These wells can be selected from those agricultural wells that have not been used for monitoring before or from those agricultural wells which are used for monitoring but have some missing data.

\subsection{Cost-Informativeness Analysis}

The cost of monitoring is a major factor that influences the design of the monitoring network. This cost may vary from place to place (developing or developed regions). Table 3 includes the cost of monitoring items for the Gaza Strip. This table has been compiled in collaboration with the PWA. As shown in the table, the overall cost of monitoring items is converted to the cost of monitoring per well. The cost of monitoring in the Gaza Strip includes:

- The operational cost of the monitoring vehicle which includes the cost of fuel and the cost of maintenance of the vehicle. According to the PWA, the existing number of monitoring wells (124) is sampled over a two-month period. An average of eight wells are sampled daily. The total distance covered in order to monitor every day eight wells is approximately $30 \mathrm{~km}$. The total amount of fuel required for completing the daily monitoring activities is around 31 . Given the

Table 3 Estimation of the cost of groundwater quality monitoring per well in the Gaza Strip

\begin{tabular}{lc}
\hline Items & Quantity (US\$/well) \\
\hline Monitoring vehicle & 2.01 \\
$\quad$ Cost of fuel & 0.23 \\
Cost of maintenance & 2.24 \\
$\quad$ Cost of monitoring vehicle $\left(\right.$ Cost $\left.^{\mathrm{V}}\right)$ & \\
Laboratory analyses & 10 \\
$\quad$ Cost of laboratory analyses $\left(\operatorname{Cost}^{\mathrm{L}}\right)$ & \\
Staff salary & 4.32 \\
$\quad$ Monitoring engineer $(1 \times 900 \mathrm{US} \$)$ & 3.36 \\
$\quad$ Technicians $(2 \times 350$ US $\$)$ & 11.51 \\
$\quad$ Data processing and reporting & \\
$\quad(2 \times 1200 \mathrm{US} \$)$ & 19.18 \\
$\quad$ Cost of the salary of monitoring & \\
$\quad$ staff $\left(\operatorname{Cost}^{\mathrm{S}}\right)$ & 31.42 \\
Total cost $\left(\operatorname{Cost}^{\mathrm{M}}\right)$ &
\end{tabular}


Table 4 Summary of the redesign scenarios and the related cost of monitoring in the Gaza Strip area

\begin{tabular}{|c|c|c|c|c|c|c|}
\hline & $\begin{array}{l}\text { a (Grid size) } \\
(\mathrm{m})\end{array}$ & $\mathrm{L}(\mathrm{m})$ & $\begin{array}{l}\text { Min. existing } \\
\text { distance }(\mathrm{m})\end{array}$ & $\begin{array}{l}\text { No. of } \\
\text { wells }\end{array}$ & $\begin{array}{l}\text { NRI } \\
(\%)\end{array}$ & $\begin{array}{l}\text { Total Cost of } \\
\text { monitoring } \\
\left(\text { Cost }^{\text {Total }}\right)(\mathrm{US} \$)\end{array}$ \\
\hline Existing situation & - & - & 48 & 124 & 85 & 3897 \\
\hline Scenario 1 & 500 & 1414 & 210 & 89 & 50 & 2797 \\
\hline Scenario 2 & 1000 & 2828 & 540 & 46 & 16 & 1446 \\
\hline Scenario 3 & 1500 & 4242 & 814 & 27 & 7 & 848 \\
\hline $\begin{array}{l}\text { Recommended } \\
\text { scenario }\end{array}$ & 958 & 2705 & 428 & 49 & 23 & 1540 \\
\hline
\end{tabular}

NRI Net redundant information

cost of fuel in Palestine, which is $0.67 \mathrm{US} \$ / 1$, the estimated fuel cost per well is 2.01 US\$. The maintenance cost per well was computed by considering the yearly maintenance cost of 700 US\$ (This cost is indicated by the PWA.). Therefore, the daily maintenance cost is 1.92 US\$ and the maintenance cost per well is 0.23 US\$ (Metcalf and Eddy 2000).

- Estimation of the monitoring cost is only made for Chloride, since the laboratory test cost per sample for Chloride is about 10 US\$ and for Nitrate 15 US\$. A discount percentage can be applied to the cost of laboratory analyses if the number of monitoring samples is increased. Consequently, the total cost of monitoring per well will decrease.

- The monitoring staff includes: one monitoring engineer, two technicians, and two engineers for data processing and reporting. The estimated cost of the salary of the monitoring staff (US\$/well) was made based on a 2-month period and 124 wells.

Table 4 summarizes the assessment and the redesign outcomes for the Gaza Strip area under the scenarios described above and the cost of monitoring for each scenario. The total cost of monitoring under the four scenarios is computed using Eq. 7. The net redundant information percentage is plotted against the total cost of monitoring in Fig. 3, which shows that, under the assumption used, there is a linear relationship between the cost of monitoring and the redundant information which is available in the monitoring network. Increasing the amount of redundant information permissible increases the cost of monitoring. If the recommended scenario is considered in which $23 \%$ of redundant information is still available in the monitoring network, the cost of monitoring will then be reduced to around 1500 US $\$$.

Fig. 3 Relation between the cost of monitoring and the percentage of the net redundant information (NRI) in the Northern Governorate (Cost-Informativeness relationship)

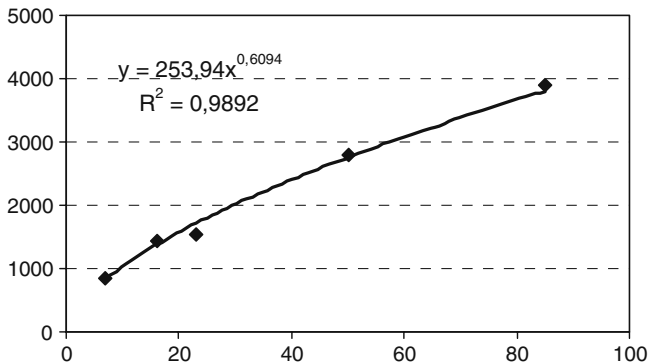


Therefore, since the monitoring is done twice a year, the Palestinian Water Authority will save around 4700 US\$ for measuring one groundwater quality variable $(\mathrm{Cl})$ in the Northern Governorate, if the recommended scenario is implemented.

\subsection{Multi-Objective Monitoring Assessment and Redesign}

$T$-Models were obtained for $\mathrm{Cl}$ and $\mathrm{EC}$ and $\mathrm{NO}_{3}$ variables and fitted to the exponential decay curve as described in Section 3.1. The exponential decay of the discrete $T$-Models for the three variables $\left(\mathrm{Cl}, \mathrm{EC}\right.$ and $\left.\mathrm{NO}_{3}\right)$ were plotted in Fig. 4. The fitting of the exponential decay curve to the discrete model was performed using the least squares fitting procedure with GRAPHPAD PRISM3 statistical software (Motulsky 1999). The coefficient of determination $\left(R^{2}\right)$ was used to quantify the goodness of fit between the exponential decay curve and discrete model data for the three variables. Table 5 shows that $R^{2}$ for $\mathrm{Cl}, \mathrm{EC}$ and $\mathrm{NO}_{3}$ were $0.45,0.28$ and 0.43 , respectively. In Fig. 4 and for EC curve, the discrete values are scattered since $R^{2}$ is low, however for the sake of comparison with the remaining two variables $\left(\mathrm{Cl}\right.$ and $\left.\mathrm{NO}_{3}\right)$ the exponential decay curve of EC can be acceptable. Note that $R^{2}$ can be increased if the number of data used are decreased. The low right corner of Fig. 4 includes the best fitted exponential decay curves of $T$ model for the three variables. Parameters of each model $\left(T_{0}, T_{\min }, K_{T}\right.$ and $\left.L_{T}\right)$ are shown in Table 5. In this table, the $L_{T}$ values are obtained using Eq. 3 and considering the value of $\varepsilon$ equal to 0.0001 Nats.
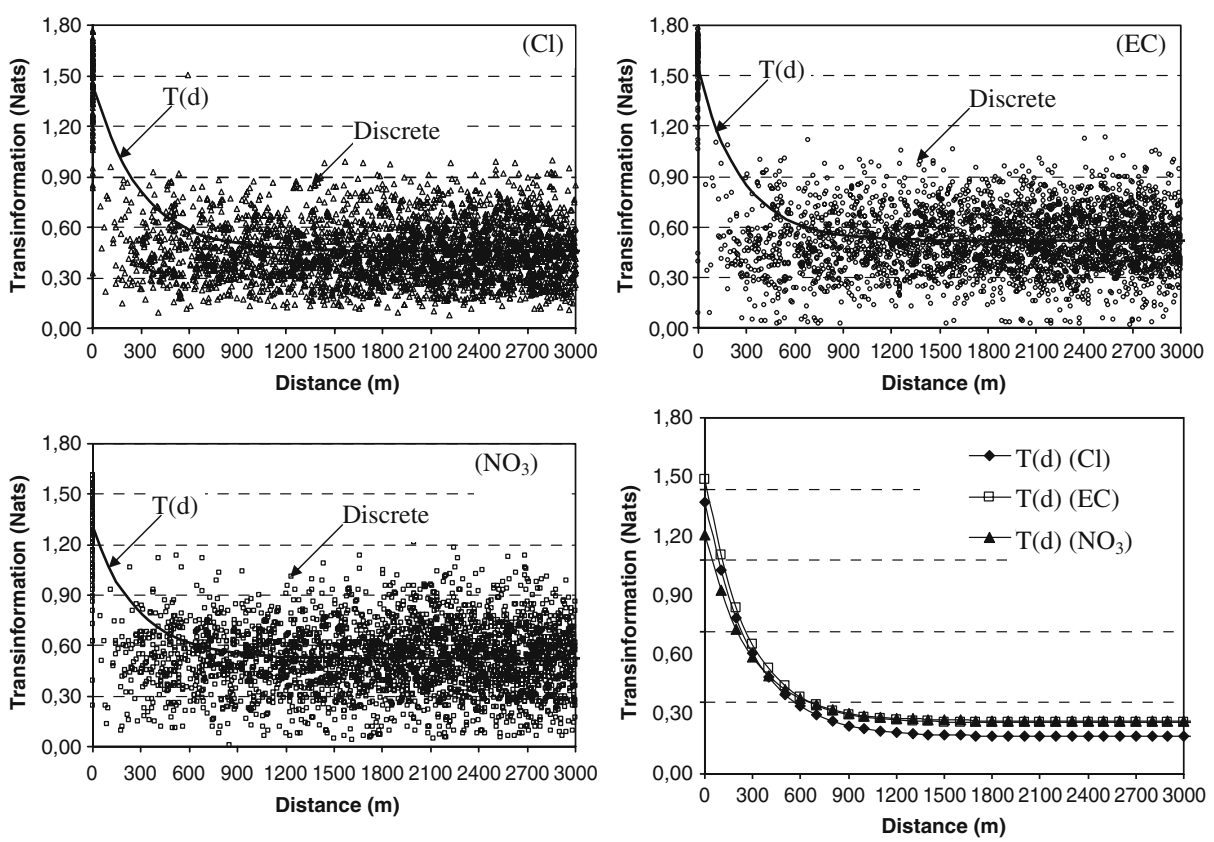

Fig. 4 Transinformation models for $\mathrm{Cl}, \mathrm{EC}$ and $\mathrm{NO}_{3}$ variables, measured in the Northern Governorate 
Table 5 Transinformation model parameters for the three variables $\left(\mathrm{Cl}, \mathrm{NO}_{3}\right.$ and $\left.\mathrm{EC}\right)$, for 124 wells in the Northern Governorate

\begin{tabular}{lllllll}
\hline Groundwater quality variables & $T_{0}$ (Nats) & $T_{\min }($ Nats $)$ & $K_{T}(1 / \mathrm{m})$ & $L_{T}(\mathrm{~m})$ & $a($ Grid size $)(\mathrm{m})$ & $R^{2 \mathrm{a}}$ \\
\hline $\mathrm{Cl}$ & 1.4443 & 0.4583 & 0.003429 & 2705 & 958 & 0.45 \\
$\mathrm{NO}_{3}$ & 1.3076 & 0.5226 & 0.003522 & 2546 & 900 & 0.28 \\
$\mathrm{EC}$ & 1.5417 & 0.5157 & 0.003754 & 2460 & 870 & 0.43 \\
\hline
\end{tabular}

${ }^{\mathrm{a} C o e f f i c i e n t}$ of determination

The same assessment approach, which was presented in Section 3.1, was also followed for $\mathrm{Cl}, \mathrm{EC}$ and $\mathrm{NO}_{3}$ variables. For these three variables, it was found that the minimum distance between existing monitoring wells is less than the range $\left(L_{T}\right)$ in the $T$-Model of each of the variables. Therefore, the monitoring network should be reduced. Equation 5 was used to compute the grid size, which is used to select the wells required to monitor $\mathrm{Cl}, \mathrm{NO}_{3}$ and $\mathrm{EC}$, based on the minimum redundant information.

To make the maximum use of existing wells, the redesign of the multi-objective monitoring network, using the superposition approach, was performed as follows:

1. The first step was to select the monitoring network for the $\mathrm{Cl}$ variable, since the grid size (a) for the $\mathrm{Cl}$ variable is greater than for $\mathrm{EC}$ and $\mathrm{NO}_{3}$ (see Table 5). Note that the same group of wells which is recommended in Section 4.1 is also suggested to monitor $\mathrm{Cl}$ in this section.

2. Since the difference in the grid size for $\mathrm{EC}$ and $\mathrm{NO}_{3}$ is only $30 \mathrm{~m}$, the same wells were used to monitor both $\mathrm{EC}$ and $\mathrm{NO}_{3}$. The wells recommended to monitor $\mathrm{Cl}$ are checked to verify if they were suitable also to monitor $\mathrm{EC}$ and $\mathrm{NO}_{3}$ by changing the grid size to $870 \mathrm{~m}$ (this grid size is used for $\mathrm{NO}_{3}$ and $\mathrm{EC}$ ). As the difference between the grid size for $\mathrm{Cl}$ and $\mathrm{EC}$ is about $88 \mathrm{~m}$, there are many wells that can be used to measure the three variables at the same time. However, there are some wells that might be suitable to measure $\mathrm{Cl}$ only and other wells are more convenient to measure $\mathrm{EC}$ and $\mathrm{NO}_{3}$. This judgment is based on: the closer the well to the center the better to measure the variable.

3. The third step is to deal with empty areas. It is recommended to cover these areas by adding new wells either to be selected from the existing monitoring network or new wells to be constructed. To reduce the complexity of monitoring the three variables and keeping in mind that the differences between grid sizes are small, the new wells are postulated to monitor the three variables. The empty areas close to the border with the Gaza Governorate are to be considered after performing the analysis of wells in the Gaza Governorate. About $500 \mathrm{~m}$ from the eastern border of the Northern Governorate were considered as a military zone and the monitoring activities are therefore forbidden.

Accordingly, the multi-objective monitoring wells can be classified into four groups: (1) wells to measure only $\mathrm{Cl}$; (2) wells to measure $\mathrm{EC}$ and $\mathrm{NO}_{3}$; (3) wells to measure the three variables together $\left(\mathrm{Cl}, \mathrm{EC}\right.$ and $\left.\mathrm{NO}_{3}\right)$; and (4) new wells to be added to monitor the three variables. The number of wells was eight wells in the first group, 12 wells in the second group, 41 wells in the third group, and ten wells in the forth group. The total number of wells which is recommended to monitor $\mathrm{Cl}$ was 49, while the total number to monitor $\mathrm{EC}$ and $\mathrm{NO}_{3}$ was 53 wells. Therefore, the reduction percentage of wells, which are recommended to monitor $\mathrm{Cl}, \mathrm{EC}$ and $\mathrm{NO}_{3}$ 


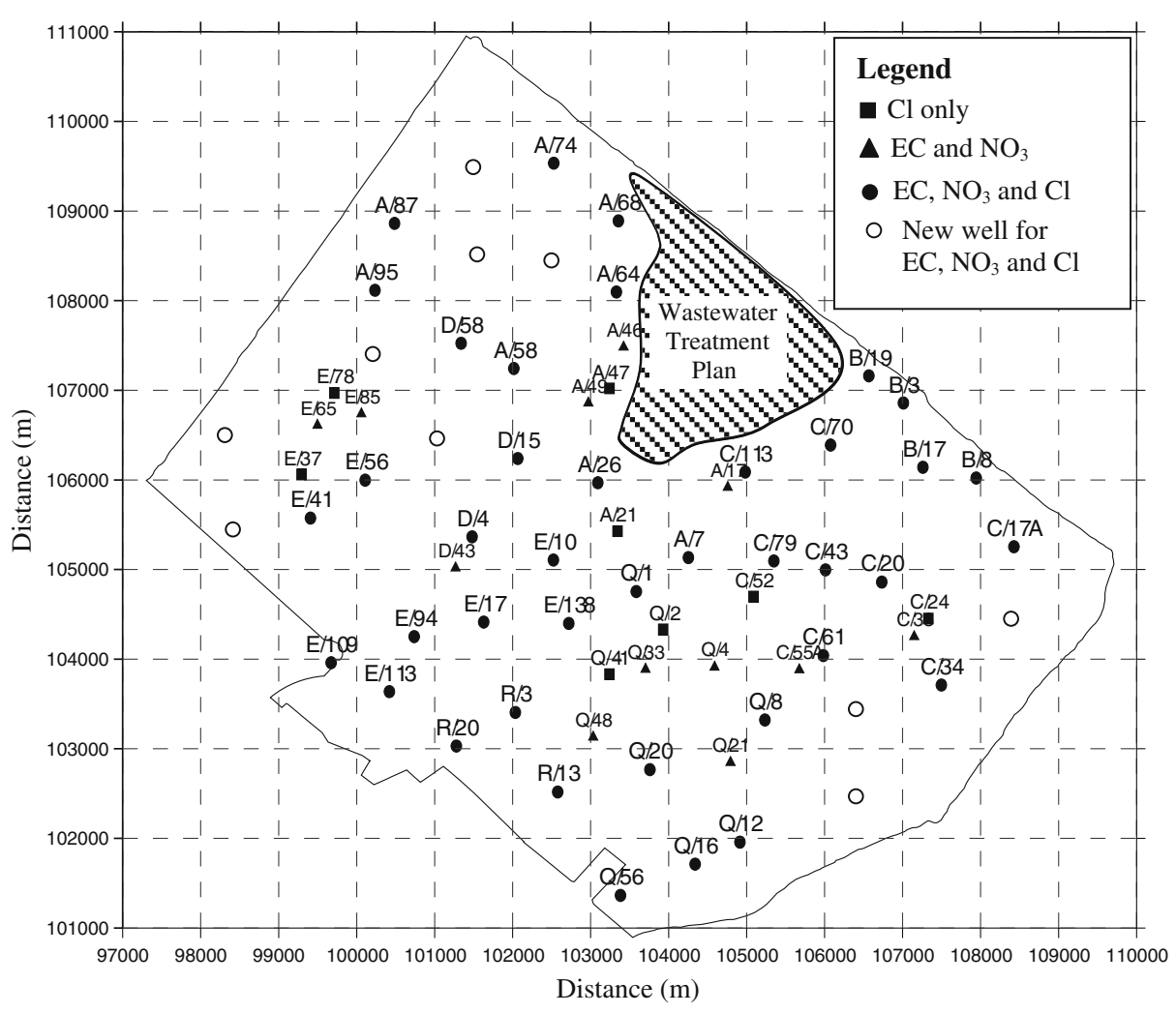

Fig. 5 The recommended location of the monitoring network for $\mathrm{Cl}, \mathrm{EC}$ and $\mathrm{NO}_{3}$ in the Northern Governorate

in the Northern Governorate, was $48 \%$. The recommended monitoring networks for the three variables are presented in Fig. 5.

\subsection{Spatial-Temporal Monitoring Analysis}

Analysing the temporal frequency of monitoring by the $T$-Model reflects the serial dependency in the time series of the data. In this section, the influence of the temporal frequency of monitoring Chloride on the parameters of the $T$-Model and consequently the design outcomes were tested. Transinformation as a function of distance was computed for all the wells in the Northern Governorate (124 wells) at different temporal frequencies (once a year in winter, once a year in summer, every 2 years in winter and every 2 years in summer) using the discrete approach. An exponential decay curve was fitted to the discrete $T$-Model data for each temporal frequency. Table 6 shows parameters of the $T$-Model for each temporal frequency. Note that $L_{T}$ values were computed using Eq. 3 and assuming the value $\varepsilon$ equal to 0.0001 . The exponential decay of the Transinformation Model $(T(d))$ of each temporal frequency is also shown in Fig. 6. 
Table 6 Influence of the temporal frequency of monitoring $\mathrm{Cl}$ on the $T$-Model parameters

\begin{tabular}{lllllll}
\hline Temporal frequency & $\begin{array}{l}\text { Size of time } \\
\text { series }(n)^{\mathrm{a}}\end{array}$ & $T_{0}$ (Nats) & $T_{\min }(\mathrm{Nats})$ & $K_{T}(1 / \mathrm{m})$ & $L_{T}(\mathrm{~m})$ & $R^{2}$ \\
\hline Twice a year (6 months) & 57 & 1.4443 & 0.4583 & 0.003429 & 2705 & 0.45 \\
Once a year (winter) & 29 & 1.3158 & 0.4719 & 0.003487 & 2659 & 0.47 \\
Once a year (summer) & 28 & 1.2969 & 0.4922 & 0.003928 & 2645 & 0.42 \\
Every 2 years (winter) & 15 & 1.3044 & 0.5967 & 0.003409 & 2607 & 0.35 \\
Every 2 years (summer) & 13 & 1.1581 & 0.5322 & 0.003641 & 2571 & 0.32 \\
\hline
\end{tabular}

The value of $\varepsilon$ equals 0.0001

a 124 wells of the Northern Governorate (Gaza Strip)

The initial transinformation $\left(T_{0}\right)$, the minimum transinformation $\left(T_{\min }\right)$, the redundant information $\left(T_{0}-T_{\min }\right)$ and the range in the $T$-Model $\left(L_{T}\right)$ at different temporal frequencies are shown in Fig. 7. This figure infers that decreasing the temporal frequency (increasing the time span of monitoring) decreases the amount of redundant information in the monitoring network. In addition, it also reflects the influence of the size of the time series. If the temporal frequency decreases, the size of the time series also decreases and consequently the serial transinformation (dependency) will decrease as well. The serial Transinformation can affect the design of the monitoring network (number of wells). Figure 7 reveals that for the Northern Governorate wells, if the temporal frequency decreases, the $L_{T}$ value decreases and the number of wells will be greater than that in the recommended scenario, where the temporal frequency was twice a year.

Figure 8 shows two curves: (1) the relation between the temporal frequency of monitoring and the number of monitoring wells, where the wells are determined based on the $L_{T}$ value in each $T$-Model of different temporal frequencies, and (2) the relation between the temporal frequency of monitoring and the cost of monitoring.

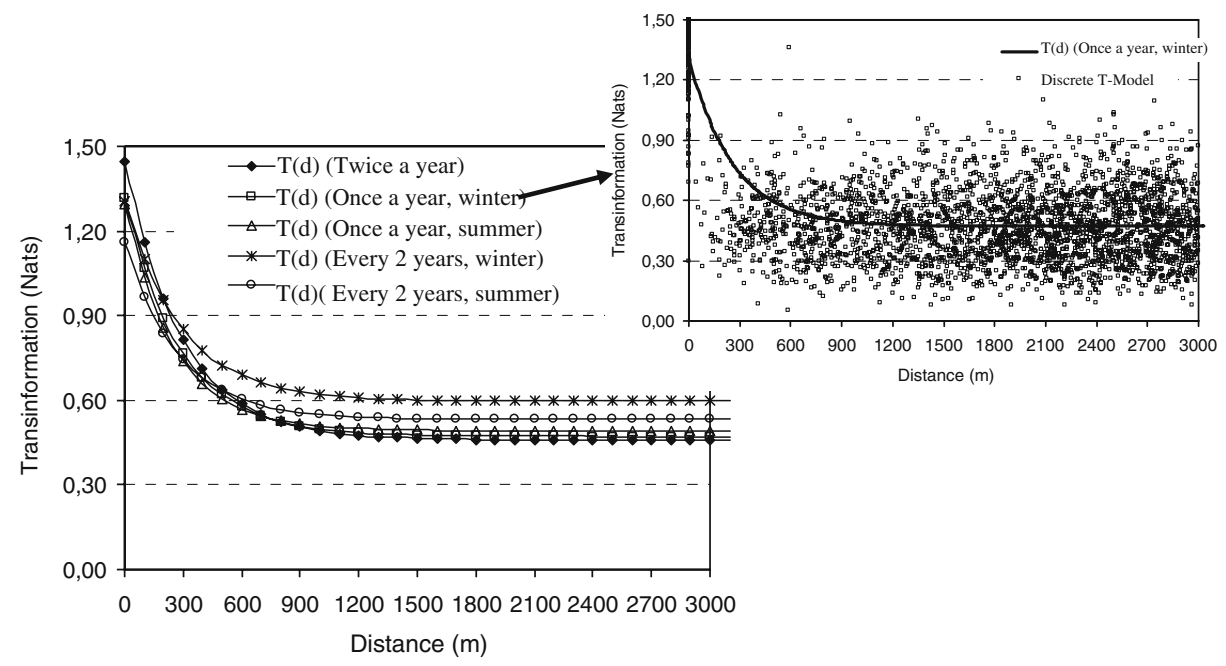

Fig. 6 Results from transinformation models for different temporal frequency of monitoring $\mathrm{Cl}$ applied to groundwater quality monitoring wells in the Northern Governorate (Gaza Strip) 

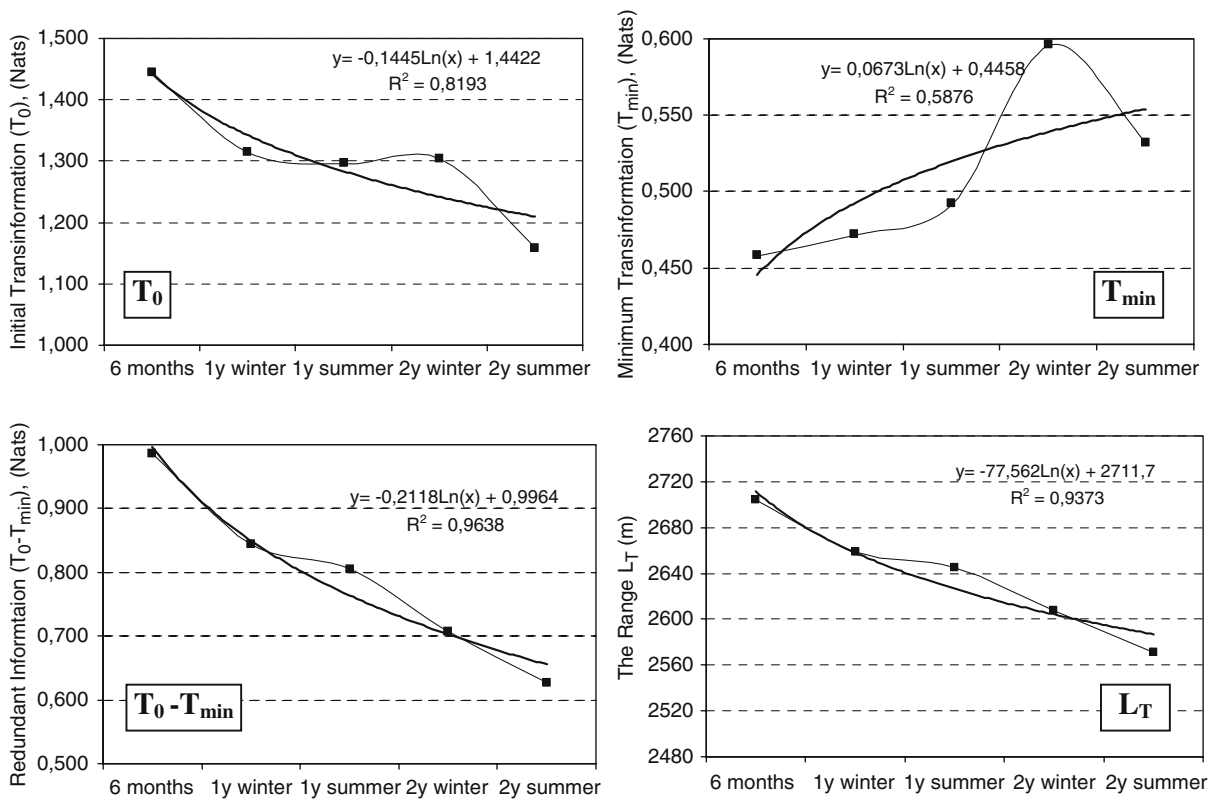

Fig. 7 The $T$-Model parameters $\left(T_{0}, T_{\min }\right.$ and $\left.L_{T}\right)$ and the redundant information $\left(T_{0}-T_{\min }\right)$ computed at different temporal frequencies applied to the groundwater monitoring wells in the Northern Governorate. In the Figure 6 months = twice a year (summer and winter), $1 y$ winter $=$ once a year at winter, $1 y$ summer $=$ once a year at summer, $2 y$ winter $=$ every 2 years at winter and $2 y$ summer $=$ every 2 years at summer

In both curves, the information related to the four times per year temporal frequency (monitoring every 3 months) is extrapolated. From Fig. 8 it can be seen that increasing the temporal frequency of monitoring decreases the number of monitoring wells. However, increasing the temporal frequency increases the cost of monitoring, since in estimating the cost of monitoring (Eq. 6), the number of monitoring per year (temporal frequency) influences the cost of monitoring per well. It means that the combination of temporal frequency and spatial location design (spatial-temporal design) indicates that decreasing the temporal frequency requires increasing the

Fig. 8 Relation between the temporal frequency of monitoring, number of monitoring wells and the cost of monitoring in the Northern Governorate. In the Figure, 3 months $=$ four times a year, 6 months $=$ twice a year, $1 y$ winter $=$ once a year in winter, 1 y summer $=$ once a year in summer,

$2 y$ winter $=$ every 2 years in winter and $2 y$ summer $=$ every 2 years in summer

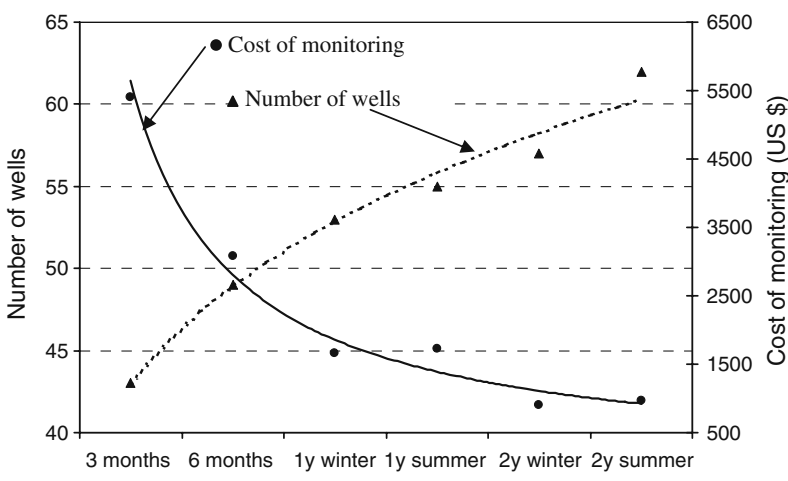


number of wells. The decision for selecting the best design options should also consider the cost of monitoring. If the number of wells, temporal frequency and cost of monitoring are considered in the design procedures, one may refer to the two curves in Fig. 8. These curves show that the recommended temporal frequency of monitoring can be twice per year, the recommended number of monitoring wells is 49 and the cost of monitoring is around 3000 US\$. If the temporal frequency is selected as four times per year then the number of wells will decrease to 43 wells and the cost of monitoring will be around 5500 US\$. It was indicated that the cost of monitoring is more affected by the temporal frequency than by the number of wells (refer to Section 4.2). For example, the cost of monitoring can be reduced to around 1500 US $\$$ if the temporal frequency is selected as one time per year. However, in the Gaza Strip, the recommended temporal frequency can be twice per year to monitor salinity in the aquifer. This temporal frequency is reasonable to investigate the overabstraction of groundwater in summer and effect of the rainfall recharge in winter.

In drawing this conclusion, the net redundant information was also included, since increasing the temporal frequency increases the redundant information (Fig. 3). In this case, the redundant information percentage was reduced to $23 \%$. This conclusion is only valid for the present situation with the monitoring cost described in Section 4.2.

\section{Conclusions}

A methodology for assessing and redesigning the groundwater quality monitoring network is postulated as a major element of this study. The net redundant information percentage was used as the criterion in the assessment stage, which revealed whether the available information is redundant, too little or enough.

The groundwater quality monitoring network in the Northern Governorate was assessed and redesigned. The Chloride data, collected over the period 1972-2000 from 124 groundwater monitoring wells in the Northern Governorate, were used in the analysis. The assessment and redesign methodology, which was based on applying entropy, can help to monitor the groundwater quality (salinity) in the Northern Governorate aquifer at a more spatially uniform level, eliminating the redundant information and consequently reducing the cost of monitoring.

The cost-effectiveness or informativeness analysis was accomplished by computing the cost of existing monitoring in the Northern Governorate and relating that to the percentage of redundant information in the monitoring network. The analysis showed that increasing the percentage of the redundant information increases the cost of monitoring.

A multi-objective design analysis showed that the entropy-based approach can be effectively applied for monitoring different variables, such as $\mathrm{EC}$ and $\mathrm{NO}_{3}$ (indicators of other pollutants). In the Northern Governorate, the reduction in the percentage of wells recommended for monitoring $\mathrm{Cl}, \mathrm{EC}$ and $\mathrm{NO}_{3}$ was $48 \%$.

The effect of the temporal frequency on the design outcomes was analyzed. It was observed that for the Northern Governorate groundwater quality monitoring wells, decreasing the temporal frequency would require increasing the number of wells. The decision to combine the spatial distribution and the temporal frequency as well as the associated minimum cost are transmitted to the decision-maker. 
The approach used in the current article should be compared to other statistical approaches and optimization approaches in order to investigate the differences in terms of advantages and disadvantages. This is part of ongoing research by the authors.

Open Access This article is distributed under the terms of the Creative Commons Attribution Noncommercial License which permits any noncommercial use, distribution, and reproduction in any medium, provided the original author(s) and source are credited.

\section{References}

Andricevic R (1990) Cost effective network design for groundwater flow monitoring. Stoch Hydrol Hydraul 4(1):27-41

ASCE (1990) Review of geostatistics in geohydrology, II: applications. J Hydraul Eng ASCE 116(5):633-658

Bueso MC, Angulo JM, Alonso FJ (1998) A state-space model approach to optimum spatial sampling design based on entropy. Environ Ecol Stat 5:29-44

Caselton WF, Zidek JV (1991) Quality data networks that minimize entropy. In: Walden AT, Guttorp P, Arlond E (eds) Statistics in the environmental and earth sciences. Wiley, Toronto, pp 11-38

Cox DD, Cox LH, Ensor KB (1997) Spatial sampling and the environment: some issues and directions. Environ Ecol Stat 4(3):219-233

Cressie NC (1990) Statistics for spatial data, revised edn. Wiley, New York, 900 pp

Gokhale D, Kullback S (1978) The information in contingency tables. Marcel Dekker, New York

Harmancioglu NB, Alpaslan N (1992) Water quality monitoring network design. Water Resour Bull 28(1):179-192

Loaiciga H (1989) An optimisation approach for groundwater quality monitoring network design. Water Resour Res 25(8):1771-1782

Loaiciga H, Charbeneau JR, Everett GL, Fogg EG, Hobbs FB, Rouhani S (1992) Review of groundwater quality monitoring network design. J Hydraul Eng ASCE 118(1):11-37

Mahar PS, Datta B (1997) Optimal monitoring and groundwater pollution source identification. J Water Resour Plan Manage ASCE 23(4):199-207

Metcalf \& Eddy (2000) Costal aquifer management program, final report: modelling of Gaza Strip aquifer. The program is funded by US Agency for International Development (USAID) and owned by the Palestinian Water Authority (PWA), Gaza, Palestine

Meyer PD, Valcchoni AJ, Eheart JW (1994) Monitoring network design to provide initial detection of groundwater contamination. Water Resour Res 30(9):2647-2659

Mogheir Y (2003) Assessment and redesign of groundwater quality monitoring networks using the entropy theory - Gaza Strip case study. Ph.D. thesis, University of Coimbra, Coimbra, Portugal, $319 \mathrm{pp}$

Mogheir Y, Singh VP (2002) Application of information theory to groundwater quality monitoring networks. Water Resour Manag 16(1):37-49

Mogheir Y, de Lima JLMP, Singh VP (2003a) Spatial structure assessment of groundwater quality variables based on the entropy theory. Hydrol Earth Syst Sci 7(5):707-721

Mogheir Y, de Lima JLMP, Singh VP (2003b) Applying the entropy theory for describing the spatial structure of groundwater regionalized variables (EC and Chloride). In: Neves MV, Neves ACV (eds) Environment 2010: situation and perspectives for the European Union. University of Porto, Portugal, pp 1-6

Mogheir Y, Singh VP, de Lima JLMP (2003c) Redesigning the Gaza Strip groundwater quality monitoring network using entropy. In: Singh VP, Yadava RY (eds) Groundwater pollution. Allied, New Delhi, pp 315-331

Mogheir Y, de Lima JLMP, Singh VP (2004) Characterising the spatial variability of groundwater quality using the entropy theory: II. Case study from Gaza Strip. Hydrol Process 18(13): $2579-2590$

Motulsky HJ (1999) Analysing data with GraphPad Prism. GraphPad Software, San Diego. www.graphpad.com 
Patrick R, Misker B, Valocchi AJ (2000) Cost-effective long-term groundwater monitoring design using a genetic algorithm and global interpolation. Water Resour Res 36(12):3731-3741

Quimpo RG, Yang JY (1970) Sampling consideration in stream discharge and temperature measurements. Water Resour Res 6:1771-1774

Radford PJ, West J (1986) Models to minimize monitoring. Water Resour 20:1059-1066

Rodriguez-Iturbe I, Mejia JM (1974) The design of rainfall networks in time and space. Water Resour Res 10:713-728

Rouhani S, Hall TJ (1988) Geostatistical schemes for groundwater sampling. J Hydrol 103:85-102

Sanders TG, Adrian DD (1978) Sampling frequency for river quality monitoring. Water Resour Res 14:569-576

Stein A, Van Groenigen JM, Jeger MJ, Hoosbeek MR (1998) Space-time statistics for environmental and agricultural related phenomena. Environ Ecol Stat 5(2):155-172

Yang Y, Burn D (1994) An entropy approach to data collection network design. J Hydrol 157: 307-324

Zhou Y (1996) Sampling frequency for monitoring the actual state of groundwater systems. J Hydrol 180:301-318 